\title{
Authors' reply re: Assisted Vaginal Birth: Green-top Guideline No. 26. (Response to BJOG-20-1437.R2)
}

\author{
Deirdre Murphy ${ }^{1}$, Rachna Bahl ${ }^{2}$, and Bryony Strachan ${ }^{2}$ \\ ${ }^{1}$ Trinity College Dublin and Coombe Women and Infants University Hospital \\ ${ }^{2}$ St Michael's Hospital, Bristol
}

September 11, 2020

Letter to the Editor, BJOG Exchange

\section{Authors' reply re: Assisted Vaginal Birth: Green-top Guideline No.26}

Dear Editor

de Leeuw \& Daly have raised a number of issues in relation to the RCOG Assisted Vaginal Birth Guideline.

1 We have responded previously to some of these issues, highlighting the short and long-term morbidity associated with vacuum and forceps assisted birth, and the relative benefits and risks of the two types of instruments. $^{2,3}$ The emphasis within an evidence-based guideline is to cite randomised controlled trials and systematic reviews of randomised controlled trials, where available, in preference to observational studies. The issues of informed consent and shared decision-making have been addressed in detail and we have responded to the suggestion that the guideline does not provide assistance to clinicians and women in line with the Montgomery ruling. ${ }^{4}$

The additional issue raised by de Leeuw \& Daly relates to routine use of episiotomy as part of assisted vaginal birth. We cited a multi-centre pilot RCT and a prospective cohort study from Scotland and England both of which showed no significant difference in the incidence OASI with routine versus restrictive episiotomy (8.1\% versus $10.9 \%$, OR $0.72 ; 95 \%$ CI $0.28-1.27$ ), and episiotomy versus no episiotomy respectively (9.9\% versus $7.7 \%$, OR $1.11 ; 95 \%$ CI $0.66-1.87)$. To date, there has been no adequately powered RCT to address this question. A number of retrospective studies have been published. de Leeuw et al published a large retrospective cohort study from the Netherlands. ${ }^{5}$ This study reported a reduced risk of OASI with episiotomy for both vacuum and forceps but of concern was the very low reported incidence of OASI in association with AVB, very different to the UK and Ireland. An overall incidence of $1.2 \%$ for vacuum assisted delivery suggests under-reporting, or under-diagnosis of OASI, and questions the reliability of the data and its applicability. Two systematic reviews of published studies came to different conclusions in relation to use of episiotomy. The breadth of the published literature on AVB and episiotomy has been presented in the guideline and the data are conflicting.

Finally, de Leeuw \& Daly have stated that the recommendation in the AVB guideline is inconsistent with the RCOG OASI Guideline. We cited directly from the OASI guideline recommendation which states the following: Mediolateral episiotomy should be considered in instrumental deliveries. [New 2015]

Deirdre J Murphy, ${ }^{1}$ Rachna Bahl, ${ }^{2}$ Bryony Strachan ${ }^{2}$

1) Coombe Women \& Infants University Hospital

Cork St, Dublin 8, Republic of Ireland

2) St Michael's Hospital, Bristol 


\section{References}

1. de Leeuw JW, Daly JO. Letter to the Editor, BJOG Exchange. (First comment letter, ref to be added)

2. Murphy DJ, Bahl R, Strachan BK. Authors reply re: Assisted Vaginal Birth: Green-top Guideline No. 26. DOI: $10.1111 / 1471-0528.16336$

3. Murphy DJ, Bahl R, Strachan BK. Authors reply re: Assisted Vaginal Birth: Green-top Guideline No. 26. DOI: $10.1111 / 1471-0528.16420$

4. Murphy DJ, Strachan BK, Bahl R, on behalf of the Royal College of Obstetricians Gynaecologists.

Assisted Vaginal Birth. BJOG 2020; https://doi.org/10.1111/1471-0528.16092

5. de Leeuw JW, de Wit C, Kuijken JPJA, Bruinse HW. Mediolateral episiotomy reduces the risk for anal sphincter injury during operative vaginal delivery. BJOG 2008;115:104-8. 